\title{
Neuropeptides: do they integrate body and brain?
}

from Susan D. Iversen

DE WIED AND BoHUS were the first to demonstrate that an extract of the posterior pituitary delayed the extinction of active shock avoidance behaviour in the rat $^{1}$. Subsequent experiments indicated that the active substance was vasopressin, and synthetic Lys $^{8}$-vasopressin given in a single dose $(3.0 \mu \mathrm{g})$ systemically caused a long-lasting delay in extinction ${ }^{2}$. These results have led to the hypothesis that vasopressin modulates processes underlying memory consolidation. If this claim were to be substantiated, vasopressin might have useful therapeutic effects in alleviating memory disorders in man, such as those seen in Korsakoff's psychosis and Alzheimer's disease.

An important question concerns the site at which vasopressin acts to produce its effects on memory. A potent analogue, $\mathrm{Arg}^{8}$-vasopressin, has a significant effect on extinction behaviour when administered intraventricularly in doses as low as 0.025 ng. When the dose-response data are compared for the subcutaneous and intracerebral routes of administration, it is clear that much smaller doses are effective when injected directly into brain ${ }^{3}$. Thus, de Wied and his colleagues favour a central nervous system (CNS) site of action. Furthermore, using immunohistochemical staining techniques it has been demonstrated that vasopressin-containing neurones of the magnocellular hypothalamic nuclei project widely to innervate various autonomic centres in the brain stem and spinal cord, and vasopressin fibres are also found in limbic septum $^{4}$. The enhanced memory performance after local injections of arginine vasopressin (AVP) into these limbic areas, has been correlated with changes in CNS noradrenaline function ${ }^{5}$. A number of intriguing facts support the hypothesis that an interaction between vasopressin and limbic forebrain noradrenaline is important for cognitive functions related to memory. Studies on human brain have recently revealed that the locus coeruleus

Susan D. Iversen is Assistant Director of Research at the Department of Experimental Psychology, Cambridge, UK.

1. De Wied, D. \& Bohus, B. Nature 212, 1484 (1966)

2. De Wied, D. Nature 232, 58 (1971).

3. De Wied, D. Life Sci. 19,685 (1976).

4. Swanson, L.W. Brain Res. 128, 346 (1977).

Kovacs, G.L., Bohus, B. \& Versteeg, D.H.G. Neuroscience 4, 1529 (1979).

6. Rossor, M.N., Iversen, L.L., Hawthorn, J., Ang, V.T.Y \& Jenkins, I.S. Lancet ii, 1367 (1980).

7. Mason, S.T. \& Iversen Brain Res. Rev. 1, 107 (1979) 8. Bondareff, W., Mountjoy, C.Q. \& Roth, M. Lancet i, 783
(1981).

9. McEntee, W.J. \& Mair, R.G. Science 202, 905 (1978)

10. Oliveros, J.C. et al. Lancet i, 42 (1978).

11. De Wied, D., Greven, H.M., L.ande, S. \& Witter, A. Br. J. Pharmac. 45, 118 (1972).

12. Smith, G.P. \& Gibbs, J. Pharmac, Biochem. Behav. 3, (Suppl 1) 135 (1975)

13. Gibbs, J. et al. Nature 282, 208 (1980).

14. Deutch, J.A. Nature 285, 592 (1980). contains the highest level of vasopressin outside the hypothalamus ${ }^{6}$. The locus coeruleus is the origin of the noradrenaline innervation of hippocampus, and lesions to this system result in learning impairments in animals when trained responses must be modified $^{7}$. Degeneration of the locus coeruleus has been observed in the brains of patients dying with Alzheimer's disease ${ }^{8}$ and degeneration of the dorsal noradrenaline pathway has been implicated in Korsakoff's disease ${ }^{9}$, an amnesic syndrome said to be improved by vasopressin treatment ${ }^{10}$.

The question of a central site of action of AVP is raised again in this issue of Nature (p.491). Le Moal and colleagues have confirmed the effects of systemic AVP on extinction behaviour in the rat, and report that a novel synthetic antagonist of AVP can abolish this behavioural effect. Within the same dose range, they also demonstrate an effect of AVP on blood pressure, which was reversed by the antagonist at doses effective against the behavioural response. The authors suggest that there is a causal relationship between the effect of AVP on blood pressure and the prolongation of extinction behaviour, and that the visceral arousal induced by AVP and reflected in the blood pressure change induces, via visceral afferents to the CNS, cerebral arousal "sufficient to alert the rat and to cause the perseverance of ongoing or escape behaviours"'.

They suggest that the reported effects of AVP on brain may also be due to peripherally triggered activation of visceral integrative centres. In the experiments where AVP has been injected into the ventricles or limbic sites, it is possible that the circumventricular organ systems may be the site of action rather than structures within the brain itself. It seems premature to reject one or other of these hypotheses. For example, the vasopressin analogue Desglycinamide lysine vasopressin, which is practically devoid of classical endocrine activity, has an effect on extinction of avoidance behaviour ${ }^{11}$. It would seem that a presser response to vasopressin is sufficient but not necessary for the effect on behaviour.

A more important implication of the paper is that vasopressin and other neuropeptides may act at both peripheral and central nervous system sites in an integrated fashion. Vasopressin released in brain would appear to act on the noradrenergic pathway arising in locus coeruleus. It is interesting that visceral afferent information reaches brain stem areas (including locus coeruleus) rich in vasopressin innervation. In certain behavioural situations visceral and central arousal, induced independently by the release of vasopressin systemically and in brain, may synergize to achieve coordinated physiological and behavioural response. A parallel example is to be found in the studies of cholecystokinin ${ }^{12}$ and bombesin ${ }^{13}$ both of which have been reported, after systemic injection, to reduce food intake in the fasted animal. Traditionally such effects are thought to involve satiety centres of the CNS, which modulate ingestive behaviour. However, Deutch $^{14}$ and his colleagues found that these peptides induce profound physiological changes in gut and suggest that the resulting malaise or strong visceral arousal is sufficient to account for the behavioural effects of these peptides. In support of this view, Deutch has reported that subcutaneously administered cholecystokinin or bombesin provides a sufficient visceral cue for conditioned taste aversion to develop.

Again, CNS activation, secondary to visceral arousal, may largely account for the behavioural effect of a peptide. The importance of the present article by Le Moal et al. is that it forces us to re-evaluate the peripheral effects of peptides in accounting for their effects on behaviour. In the past decade it has been exciting to discover that a large number of peptides, with established endocrine and physiological functions, exist in brain. Perhaps we have too readily assumed that their behavioural effects reflect direct actions on the CNS.

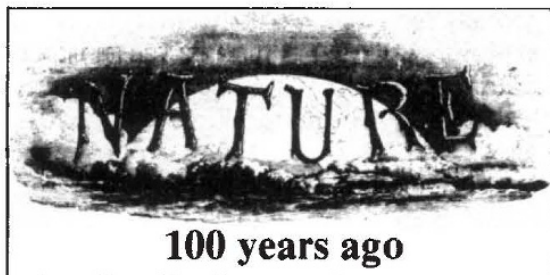

Mr. Josceline Bagot and Mr. Drummond, of the Grenadier Guards, accompanied by Mr. $\mathrm{T}$. Wright, the winner of the International Balloon Contest, went up in a balloon from the Crystal Palace on the 1st inst. at 1 p.m. When the ropes were loosed they ascended to the height of 5000 feet, and travelled slowly in a south-westerly direction for the distance of about eight miles. The balloon then suddenly sank, but ballast being thrown out, it rose again to 8000 feet, and traversed in the direction of Epsom. The aëronauts then descended in a field about a quarter of a mile from the Grand Stand, which they reached in time to witness the race for the Derby.

An opera performed on the stage of the Paris Grand Opera House was heard satisfactorily at the Rue Riche Opera House by a number of French officials a few days ago. The feat was performed with the new Ader telephone, of which the peculiarities have not been made public. The performance will be repeated at the International Exhibition.

from Nature 24, 9 June, 132, 1881 